\title{
FACTORS AFFECTING MOBILE SHOPPERS' CONTINUATION INTENTION OF COFFEE SHOP ONLINE STORE: A PERSPECTIVE ON CONSUMER TOLERANCE
}

\author{
Chien-Wen Chen \\ Feng Chia University, \\ No. 100 Wenhwa Rd., Seatwen, Taichung, Taiwan 40724, R.O.C. \\ chencw@fcu.edu.tw \\ Serhan Demirci* \\ Feng Chia University \\ No. 100 Wenhwa Rd., Seatwen, Taichung, Taiwan 40724, R.O.C. \\ serhandemirci@gmail.com
}

\begin{abstract}
Previous studies have shown that mobile shoppers' continuation intention is highly related with whether consumer expectations are confirmed or not. This study demonstrates that the variables related with mobile shopping continuation are navigability, information quality, security, fluency, visual appeal, and reputation, which then can be categorized into three groups as structural, functional, and representational constructs. Building on the perspective of consumer tolerance, mobile shoppers with different shopping orientations are categorized into three groups based on their level of tolerance towards proposed website constructs. The findings indicate that mobile shoppers with utilitarian-orientation will tolerate performance of representational aspects of the coffee shop website, while mobile shoppers with hedonic-orientation will tolerate performance of functional aspects. Our findings provide valuable insight to the owners of coffee shops with online stores to better maintain and apply their budget while developing online stores.
\end{abstract}

Keywords: Mobile Shopping Continuance, Expectation-Confirmation Model, Consumer Tolerance, Mobile Shoppers, Shopping Website. 


\section{INTRODUCTION}

In recent years, coffee industry is rapidly moving towards ecommerce, and more specifically mobile shopping. For instance, Starbucks has started to deliver food and beverages through its mobile app ordering service in order to maintain their first move advantage as they name it "ecommerce on steroids". Similarly, Nescafe the biggest retailer of instant-coffee products in the world has moved its entire web presence to Tumblr, a social networking platform highly popular within millennials and young generation, with the sole purpose of driving ecommerce sales. Nescafe hopes that Tumblr will bring a mobile advantage in boosting their online sales, while setting the company apart from their competitors ${ }^{2}$. Local coffee shops are following the same trend as well, building online stores with mobile functionality getting more convenient with many emerging platforms $^{3}$. In this paper, we refer to these mobile stores as coffee shop online stores. Coffee shop online stores include websites with mobile ecommerce functionality, or mobile shopping apps where coffee shops create an account and use the platform for selling their products.

Mobile shopping has enabled an "anywhere, anytime" culture and enhanced the convenience of shopping 4 . Many consumers are using smartphones to reduce their effort while making purchases in stores or online $^{5}$. Mobile shopping is the driving force in ecommerce. In China, the world's largest ecommerce market, it is expected that by the end of 2018 more than $75 \%$ of ecommerce sales will be transacted via mobile devices ${ }^{6}$. Worldwide retail ecommerce sales have reached more than $\$ 2$ trillion in 2017. The growth in ecommerce is driven by the increasing comfort with mobile shopping, greater spending by consumers and the expansion in the variety of goods being purchased.

As more coffee shops are leaning towards mobile shopping, the continuation intention of consumers with a mobile shop requires further exploration. It is necessary to understand which factors affect consumers' continuation intention in engaging with a coffee shop mobile store over time, both from academic and coffee industry perspectives. Coffee is a commodity which is characteristically retailed on a regular or continuous basis. For that reason, it is reasonable to argue that mobile shoppers' continuation intention in relation with a coffee shop mobile store is significantly important. Attracting coffee shop consumers to make purchases on the mobile store is only the first step in achieving information system (IS) success; retaining these consumers is the most vital aspect ${ }^{7}$. 
Thus, it is meaningful to explore the motivations driving the continued usage of coffee shop online stores.

Mobile shopping is the application of buying goods or services by using a mobile device which is connected to the Internet through mobile or wireless networks ${ }^{8}$. In comparison with ecommerce, mobile shopping offers a higher level of convenience since it allows access to products and services anywhere and anytime ${ }^{9}$. Basically, a mobile store is a form of information system, in which mobile store continuation intention can be studied within the domain of information system continuance. Information system continuance is defined as users' intention to continue using information systems (IS).

Previous studies have explored the factors that predict information system continuance. One of the primary antecedents to IS continuance is usefulness. Bhattacherjee ${ }^{10}$ argues that users' continuance intention is determined by their satisfaction with IS use and perceived usefulness of continued IS use. User satisfaction is influenced by their confirmation of expectation from prior IS use and perceived usefulness. Bhttacherjee's proposed model ECM in information systems continuance is one of the earliest efforts to conceptualize the relationship between acceptance and continuance behavior ${ }^{11}$. Several other studies in different IS domains have shown evidence of the explanatory capacity of the $\mathrm{ECM}^{12,13,14}$.

Although previous studies have contributed to our understanding of factors that influence continuance intention, there is a lack of research concerning which factors or practices should be applied to maintain continued mobile shopping experience ${ }^{15}$. Especially from the perspective of coffee shop online stores, it is significantly important to understand which factors influence users' continuance intention. Based on research by Kim et al. ${ }^{16}$, this paper takes structural, functional, and representational aspects as the main mobile store factors. To weigh the relative importance of these factors, we further analyze the results, based on different customer segments.

Although, there is a wealth of research on customer segmentation, our understanding of customer segmentation within coffee shop online store domain is limited. Based on the zone of tolerance theory by Miller ${ }^{17}$, and customer shopping orientations by Wolfinbarger and Gilly ${ }^{18}$, this study utilizes the concepts utility-oriented, hedonic-oriented and intermediary (i.e. showing both utilitarian and hedonic characteristics) customers as three segments. 


\section{THEORETICAL BACKGROUND}

\subsection{The Zone of Tolerance}

The zone of tolerance is described as customer's tolerance for disparity between desired and adequate levels of service performance. The desired level refers to the service performance the customers hope to receive, whereas the adequate level is what customers find acceptable. Miller ${ }^{17}$ proposed that the zone of tolerance is made up of a continuum between these two ends. Figure 1 shows the zone of tolerance constituted by the two ends of the continuum. The top-end plots a consumer's desired level of service and the bottom-end labels her/his minimally acceptable level of service.

\begin{tabular}{|c|c|}
\hline Desired service & \multicolumn{1}{|c|}{$\begin{array}{c}\text { Delight } \\
\text { More than adequate }\end{array}$} \\
\cline { 3 - 3 } Zone of tolerance & $\begin{array}{c}\text { Satisfaction } \\
\text { Adequate performance }\end{array}$ \\
\hline Adequate service & $\begin{array}{c}\text { Dissatisfaction } \\
\text { Less than adequate }\end{array}$ \\
\hline
\end{tabular}

Figure 1. The Zone of tolerance

Service performance below the point of adequacy will lead to consumer dissatisfaction and decrease in her/his likelihood of continuing to use that service, while a service performance above the desired level will result in consumer satisfaction and increase likelihood of her/his intention to continue using that service ${ }^{19,20}$. Within the zone of tolerance, customers are neither satisfied nor dissatisfied with service performance ${ }^{21}$. In other words, customers may accept fluctuations in service performance; any increase or decrease in performance within the zone of tolerance causes only a marginal effect on satisfaction ${ }^{22}$.

Quality of an information system is based on system quality (technical components) and information quality (contents of the information in the system), such as software functionality, accessibility, flexibility, response 
time, reliability, ease of use, and ease of learning ${ }^{23}$. The delivery of information occurs only if the system operates without failure. This indicates that providing users with a stable system is a minimum requirement to be expected by users (i.e. adequate service, the bottom line). Only if the system operates properly, users will be able to evaluate whether the information provided by the service meets their expectations (i.e. desired service, upper line) or not. Moreover, if the system quality is adequate, then information quality becomes the consumer's major focus ${ }^{24}$. Thus, increases in system quality within the zone of tolerance does not guarantee satisfaction or continuance intention, as the consumer is focusing more on information quality rather than system quality.

\subsection{Consumer Shopping Orientations}

Consumer shopping orientation refers to the general inclination of consumers toward acts of shopping ${ }^{25}$. Two major types of consumer shopping orientations are utilitarian and hedonic ${ }^{26}$. Wolfinbarger and Gilly ${ }^{18}$ argued that consumer's online shopping behavior differs based on their motivations whether they are goal directed (i.e. for efficiency, or utilitarian oriented), or experiential (i.e. for fun, or hedonic orientated). Shopping orientation encompasses attitudes toward shopping that create a style that will influence the customer's decisions ${ }^{27}$.

The utilitarian shopping orientation is described as task-oriented, efficient, and rational, where consumers describe utilitarian shopping as "work" and carried out "due to necessity". Utilitarian value results from a conscious pursuit of an intended outcome, and is mostly task-oriented and rational ${ }^{28}$. Utilitarian-oriented consumers do not think of shopping as a recreational activity, but, rather treat shopping as a transaction that needs to be fulfilled, or accomplish a purpose. Thus, utilitarian-oriented consumers desire to accomplish their purchase quickly and without distraction. They are more efficient and rational with a focus on task completion.

The hedonic shopping orientation is described as shopping behavior with a desire to be entertained, to have fun and to derive some inherent enjoyment from the shopping activity ${ }^{18,29}$. Hedonic value is more subjective and personal than its utilitarian counterpart, and results more from fun and playfulness instead of task completion ${ }^{28}$. Unlike utilitarian shopping orientation, hedonic-oriented shopping activities are performed with no stated goal in mind. For example, consumers may aimlessly surf different shopping websites searching for auctions, hobby-type searches and hunting 
for bargains. Hedonic orientation shopping is associated with surprise, uniqueness and excitement.

Babin et al. ${ }^{28}$ proposed that consumer activities may produce both utilitarian and hedonic outcomes. Despite the distinction between the utilitarian and hedonic shopping orientations, consumers possess both orientations during their shopping activities. Because mobile commerce is an extension or a subset of electronic commerce ${ }^{30}$, we posit that mobile consumers share similar characteristics with online consumers and that the utilitarian and hedonic shopping orientations are also applicable to mobile consumers.

Prior studies have found that perceived usefulness predicts the utilitarian shopping orientation and perceived value determines the hedonic shopping orientation. $\mathrm{Wu}$ and $\mathrm{Lu} 31$ have shown that extrinsic motivators (like usefulness) is related with utilitarian-orientation and intrinsic motivators (like enjoyment, pleasure, playfulness) are related with hedonic-orientation. The perceived usefulness measures the degree to which a consumer believes that using an online shopping system will enhance instrumental value, such as price comparison, decision making or shopping efficiency. On the other hand, perceived value evaluates the entertainment and emotional aspects of online shopping, that is non-instrumental, experiential, and affective value 32 . Babin et.al 28 has found that expressions of pure enjoyment, excitement, captivation, escapism, and spontaneity are fundamental aspects of hedonic shopping value. Visual appeal or brand reputation are more valuable for the hedonic-oriented consumers as they shop to seek value according to pleasure, excitement and high-arousal stimuli. Mathwick et. al.32 has shown experiential shoppers (i.e. hedonic-oriented), are looking for heightened enjoyment in the process of shopping, meaning this type of customers are looking for inherent enjoyment of the shopping experience, such as visually appealing designs and excitement from brand reputation.

\subsection{Website Constructs}

Kim et al. ${ }^{16}$ proposed that the same metrics applied to evaluate quality of buildings in the real world can also be applied as means to measure quality of Internet businesses. They have come up with three constructs, namely as structural, functional, and representational. The structural construct indicates that Internet businesses need to be stable internally and secure externally. Customers often perceive risks and concerns in regards to mobile shopping applications ${ }^{33}$. Customers are concerned about security, 
referring to a possible loss of personal information or money, and performance meaning mobile application works flawlessly without latency or other setbacks ${ }^{34}$. Structural firmness is an important quality construct for coffee shop online stores, because customers want to feel safe and secure before they initiate any transactional activities.

The functional construct implies that Internet businesses should provide convenient functions in the information-gathering and order-processing phases. Providing convenient functions for customers to complete their intended business activities is an important architectural construct for Internet business. Perceived usefulness and perceived ease of use are the important antecedents to information system use $\mathrm{e}^{35}$, and this is applicable to coffee shop online stores as well.

Finally, the representational construct indicates that they need to provide a pleasant interface both to the system and to those using it. Representational delight is an important architectural construct of coffee shop online stores, because it enhances customers' esthetic experience as they learn to browse and find relevant in-formation.

\subsection{Continuance Intention}

Based on Expectation Confirmation Theory (ECT) expectation-confirmation model is a widely accepted tool in explaining user satisfaction and information system continuance intention ${ }^{10}$. Expectation Confirmation Theory suggests that consumers follow a process in which they make a repurchase decision. This process starts with an initial expectation about the product or service. Then consumers form perceptions about the performance of the product or service, and make comparisons with their original expectations. Whether or not the perceived performance meets the original expectations will determine the level of satisfaction. Eventually, satisfied customers form a repurchase intention, while dissatisfied customers withdraw from continuing to use in the future ${ }^{36}$.

Bhattacherjee ${ }^{10}$ extended Expectation Confirmation Theory to build the Expectation-Confirmation Model of IS continuance. He posits that perceived usefulness and user satisfaction lead to continuance intention to use. Perceived usefulness along with confirmation of expectations from prior use leads to user satisfaction. Confirmation also influences perceived usefulness. In other words, users' intentions to continuously use an information system depend on system usage satisfaction as well as the usefulness of that system. Confirmation is a tradeoff between users' 
expectations of system usage and the actual performance of the system. If the latter outperforms the former, then users are able to confirm that the performance of the system fits their expectations of that system. Thus, confirmation is hypothesized as the determinant affecting users' subsequent expectations (i.e., perceived usefulness) and enduring attitudes toward using that system (i.e., satisfaction). This enduring attitude toward system usage is not only influenced by confirmation but is also affected by perceived usefulness if users believe that the system enhances their job performance.

ECM has been applied to investigate continuance intention in different fields. For instance, Lee ${ }^{12}$ derived an extension of ECM with technology acceptance model (TAM) in an empirical study to predict users' continuance intention of e-learning. Similarly, Hsu and $\operatorname{Lin}^{37}$ have used ECM with perceived value to examine the purchase intentions for paid mobile applications in mobile commerce. Thong et al ${ }^{38}$ developed an expanded model of IT continuance examining mobile internet services. Lee and Kwon ${ }^{39}$ investigated the effect of cognitive and affective factors in relation with continuance intention expanding ECM. Consistent with these studies, the present study applies ECM as the principal part of our research model so that the proposed determinants of mobile shopping continuance can be prioritized.

\section{RESEARCH MODEL AND HYPOTHESES}

Figure 2 illustrates our research model. The left-hand side of the model is related to the website constructs: namely structural, functional, and representational constructs. The right-hand side of the model presents coffee shop online store continuance intention replicated from the expectation-confirmation model and its extended version by Lin et al. ${ }^{40}$. 


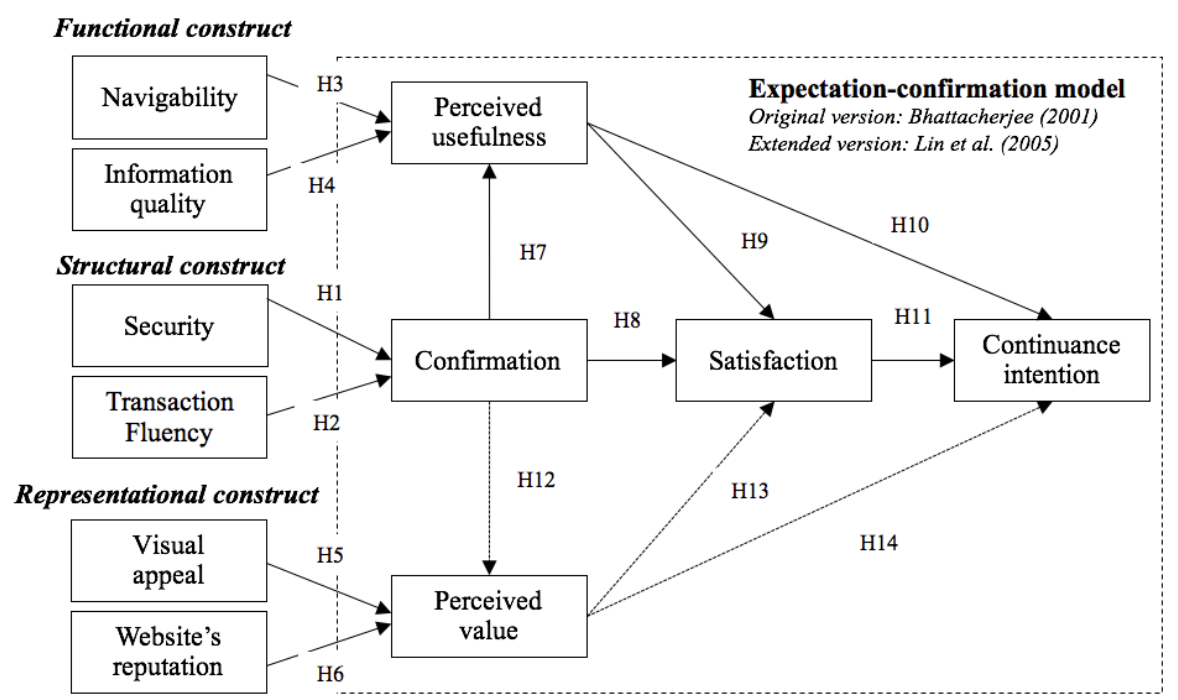

Figure 2. Research model.

\subsection{The Structural Construct and Confirmation Relationship}

There are two structural sub-constructs presented in our research model: security, and transaction fluency. Customers have higher perceived risk and concern about security in regards to mobile shopping applications ${ }^{33}$. In comparison to other e-commerce transactions, mobile shopping involves more uncertainty and risk $^{41}$. For instance, the wireless technology-based mobile systems are more vulnerable to information interception ${ }^{42}$. The security sub-construct has become increasingly important in mobile shopping because it has to do with the safety of exchanged information, such as personal ID and credit card number ${ }^{43}$. Security includes the protection of data against accidental or intentional disclosure of personal and financial data to unauthorized parties. Customers' concerns with monetary losses on mobile applications have a significant effect on acceptance and continuance intention ${ }^{44}$. This implies the importance of providing consumers with a safe online transaction in online mobile shopping experience ${ }^{45}$. Following the association between perceived performance and confirmation ascertained by $\mathrm{Oliver}^{46}$, we postulate that consumers' perceptions of mobile shopping security determine their confirmation of overall website performance. Mobile consumers should therefore share similar security concerns with online consumers such that a 
shopping website is said to perform well if it provides security protection. In other words, the overall performance of a mobile shopping website can be confirmed when ubiquitous transactions over mobile devices are protected and free from security threats. We therefore propose the following hypothesis:

H1. Security is positively associated with mobile shoppers' confirmation of website performance.

Transaction fluency is another structural sub-construct which refers to a mobile website working flawlessly without interruptions. Although high speed cellular networks (i.e., 4G or LTE) are widely available and mostly reliable, order and payment transactions made on these networks are not error free, and seen as less stable than a fixed internet connection ${ }^{47}$. For many consumers, the fluency of transaction is most critical in situations where shopping is interrupted due to connectivity problems ${ }^{38}$. Especially in the early stages of mobile shopping reliability or function of the network was the biggest concern for consumers. System dependent risks related with environmental uncertainty of mobile transaction and unpredictable nature of online payment technology are major concerns for mobile shopping consumers $^{48}$. Consumers' concerns related with mobile shopping transactions is a major barrier to the adoption of mobile shopping ${ }^{34}$. On the other hand, consumers find high performance of a mobile shop as a proof of its usefulness, and are more willing to continue to use ${ }^{45}$. Therefore, we propose:

H2. Transaction fluency is positively associated with mobile shoppers' confirmation of website performance.

\subsection{The Functional Construct and Perceived Usefulness Relationship}

The simplicity of mobile shopping enables consumers to find and purchase the products they desire easily and conveniently ${ }^{49}$. Navigability is an essential property of mobile shopping. As a functional construct, it refers to the ease of moving between or within the pages of a website ${ }^{50}$. Yang et al. ${ }^{51}$ argued that navigability supports the online shopping process as navigating difficulties hinder consumers from obtaining desired information. Easy-to-use systems are more likely to be used than the inconvenient ones ${ }^{52}$. 
When navigating difficulties persist, consumers may stop shopping on the website. Simplicity of mobile shopping experience has found to be a key factor for consumers to switch to a different provider ${ }^{53}$. Thus, coffee shop websites should provide consumers with ease of navigation that assists them to find what they need without difficulty ${ }^{54}$. Because navigability allows consumers to successfully seek for needed information, a website with ease of navigation is considered to be useful for consumers who are evaluating the importance of shopping information if its relevance is not immediately significant. With advances in mobile technologies, it is crucial for users to search for information they need in an easy manner, and simplicity is a much more important indicator than ever for new mobile-enabled services ${ }^{55}$. We therefore propose the following hypothesis:

H3. Navigability is positively related to mobile shoppers' perceptions of website usefulness.

Information quality is another functional construct representing the quality of information offered by the coffee shop website ${ }^{56}$. Information richness allows users to perceive richness and diversity of information collected through online media and affects customers' attitudes and behavioral intention to use mobile shopping ${ }^{57}$. The amount of information offered on a mobile website arouse intention to switch to using mobile websites $^{58}$. Availability of information on a mobile shopping website has the benefits of reducing uncertainty in purchasing decisions, help to find best price and acquire information more efficiently and conveniently ${ }^{59}$. On the other hand, mobile technology offers flexible and ubiquitous reach to information. Through mobile technologies consumers are able to search for a wide range of information and data without the limitations of time and place $^{60}$.

The most commonly used attributes for measuring information quality are accuracy, currency, relevance, completeness and understandability ${ }^{61}$. Accuracy refers to consumers' perceptions that information is correct, while currency addresses consumers' perceptions that the information is new and frequently updated. Relevance, on the other hand, refers to whether the presented information is concerned with the interests of consumers, while completeness pertains to whether a website provides all the necessary information. Finally, understandability refers to the ease with which consumers understand a coffee shop website's content. Shopping websites 
that maximize these variables are likely to provide consumers with other usage benefits, such as product comparison and decision aids ${ }^{62}$.

For example, a consumer who has limited knowledge about coffee beans, differences in flavors or brewing methods, can rely on the online store's recommendations about the most relevant products ${ }^{63}$. Because information can be regarded as any content produced by the website that delivers required information to consumers ${ }^{64}$, information with the attributes of accuracy, currency, relevance, completeness, and understandability are considered to be useful for online consumers in terms of enhancing her/his shopping performance ${ }^{65}$.

Previous studies have validated the relationship between information quality and perceived usefulness in the fields of information system usage ${ }^{66}$ and online shopping ${ }^{62}$, however, there is little research that pays attention to exploring such a relationship in the context of mobile shopping continuance. We therefore propose the following hypothesis:

H4. Information quality is positively related to mobile shoppers' perceptions of website usefulness.

\subsection{The Representation Construct and Perceived Value Relationship}

Aesthetics is significantly important within coffee shop setting. In the retail context, aesthetics contains two dimensions: visual appeal elements and dramatic aspects of the retail environment ${ }^{67}$. Visual appeal is triggered by the design, physical attractiveness and beauty inherent in the coffee shop retail setting, while dramatic aspects reflect an appreciation for the retail spectacle, such as a swarm of consumers purchasing products from a reputable store ${ }^{68}$. Both visual appeal and dramatic aspects offer immediate pleasure for its own sake, irrespective of a coffee shop environment's ability to facilitate the accomplishment of a specific shopping task ${ }^{69}$. Research on recommender systems show that visual presentation significantly improves user's satisfaction and continuance intention ${ }^{70}$.

With regard to online shopping, there are various graphic layouts with different colors that photographically represent products on a shopping website $^{71}$. Previous research shows that the perceived quality of the mobile store is positively correlated with the attractiveness of the mobile store ${ }^{72}$. 
Consumers tend to buy products from shopping websites with good reputations ${ }^{73}$ or from shopping websites with third-party endorsements ${ }^{74}$. Both have little to do with a coffee shop website's ability to facilitate the support of a consumer's shopping tasks and so imply the need to elaborate on the impact of aesthetics on the representation of a website, because consumers' perceived value can be predicted by the benefits that are derived from their perceptions of playfulness, enjoyment or even the aesthetic of a shopping website ${ }^{75}$. In other words, perceived value is reflected in a consumer's appreciation of the aesthetics intrinsic to a consumption setting that are manifest in the visual appeal or other representational images (e.g., brand name, brand reputation) of a shopping experience ${ }^{76,77}$. Cretu and Brodie $^{78}$ also report that a company's reputation has a significant influence on perceptions of customer value. Because visual appeals are amendable to pursuing consumers ${ }^{79}$ and brand reputation is transferable from coffee shop's offline retail store to their online store ${ }^{80}$, we propose the following two hypotheses:

H5. Visual appeal is positively related to mobile shoppers' value perceptions of using the shopping website.

H6. Website reputation is positively related to mobile shoppers' value perceptions of using the shopping website.

\subsection{Hypotheses of The Expectation-Confirmation Model}

ECM asserts that a user's intention to continually use a system is determined by her/his perceived usefulness and satisfaction. Satisfaction and perceived usefulness are in turn affected by the degree to which the user's expectations about the information system are confirmed. Customer satisfaction is positively linked to the behavioral intention to continue using $\mathrm{IS}^{81}$. Examining students using an online learning system, Chiu et al. ${ }^{82}$ found that higher satisfaction lead to greater intention to continue using the system. Similarly, in line with other previous studies that have validated the relationships found in $\mathrm{ECM}^{10}, 12,13,38,83,84$, we propose the following hypotheses in the mobile shopping context of coffee shop websites:

H7. The extent of confirmation perceived by mobile shoppers is positively associated with their perceptions of coffee shop website usefulness. 
H8. The extent of confirmation perceived by mobile shoppers is positively associated with their satisfaction with coffee shop website use.

H9. Mobile shoppers' perceptions of website usefulness are positively associated with their satisfaction with coffee shop website use.

H10. Mobile shoppers' perceptions of website usefulness are positively associated with their intentions to continually use that coffee shop website.

H11. Mobile shoppers' satisfaction with website use is positively associated with their intentions to continually use that coffee shop website.

However, not all users are concerned with the utilitarian aspects of a system; instead, some users may focus on other hedonic perceptions elicited from system usage. Batra and Ahtola85 showed that while the utilitarian-oriented users are associated with more instrumental, functional attributes, the hedonic-oriented users are associated with sensory, experiential product attributes. Similarly, $\mathrm{Wu}$ and $\mathrm{Lu} 31$ have shown that extrinsic motivators (like usefulness) is related with utilitarian-orientation and intrinsic motivators (like enjoyment, pleasure, playfulness) are related with hedonic-orientation. Mathwick et. al.32 has shown experiential shoppers (i.e. hedonic-oriented), are looking for heightened enjoyment in the process of shopping, meaning this type of customers are looking for inherent enjoyment of the shopping experience, such as visually appealing designs and excitement from brand reputation. Lin et al.40 added the construct of perceived playfulness into ECM in order to better understand the hedonic aspects of web system continuance (see dash lines in Figure 2). In the current study, we adopt perceived value as a surrogate of perceived playfulness. The factors within Representational Construct, visual appeal and website reputation are recreational or emotionally arousing which correlates to perceived value. We therefore propose the following hypotheses in the mobile shopping context, which are replicated from the extended version of ECM proposed by Lin et al.40:

H12. The extent of confirmation perceived by mobile shoppers is positively associated with their value perceptions when using a coffee shop website.

H13. Mobile shoppers' value perceptions when using a website are positively associated with their satisfaction when using that coffee shop website. 
H14. Mobile shoppers' value perceptions when using a website are positively associated with their intentions to continually use that coffee shop website.

\section{DATA COLLECTION AND ANALYSIS}

\subsection{Data Collection}

The data for the current study were collected through a Web-based questionnaire and the primary unit of analysis is concerned with consumers who have had mobile shopping experience on a coffee shop website. The survey lasted for three weeks. By the time the survey was concluded, 358 questionnaires were collected. The exclusion of 12 invalid questionnaires resulted in a total of 346 complete and valid questionnaires for further analysis. Among the usable sample, $52 \%$ of the respondents were female, $48 \%$ were male, and $47.4 \%$ were students. Most of the respondents were in the 19 to 24 -year age group $(54.9 \%)$. With regards to mobile shopping experiences, $37.3 \%$ of the respondents stated that they had made at least two mobile purchases, while $31.8 \%$ cited three purchases. Table 1 summarizes the attributes of the respondents.

Table 1. Demographics (number of respondents $=346$ ).

\begin{tabular}{llrr}
\hline Measure & Items & Frequency & Percentage \\
\hline \multirow{3}{*}{ Gender } & Male & 166 & 48.0 \\
& Female & 180 & 52.0 \\
\hline \multirow{3}{*}{ Age } & Under 18 & 13 & 3.8 \\
& $19-24$ & 190 & 54.9 \\
& $25-35$ & 128 & 37.0 \\
& $36-45$ & 6 & 1.7 \\
& Over 45 & 9 & 2.6 \\
\hline \multirow{3}{*}{ Occupation } & Full-time student & 164 & 47.4 \\
& Military, public service, and education & 14 & 4.0 \\
& Finance & 9 & 2.6 \\
& Communication & 12 & 3.5 \\
& Freelance & 4 & 1.2 \\
& Service industry & 79 & 22.8 \\
& Information industry & 11 & 3.2 \\
& Agricultural/forestry/fishing/herding & 8 & 2.3
\end{tabular}




\begin{tabular}{llcr}
\hline & Manual laborer & 25 & 7.2 \\
& Specialist & 8 & 2.3 \\
& Other & 12 & 3.5 \\
\hline \multirow{3}{*}{ Education } & Junior high school or under & 1 & 0.3 \\
& High school & 28 & 8.1 \\
& University & 252 & 72.8 \\
& Graduate school or above & 65 & 18.8 \\
\hline \multirow{5}{*}{ Experience with } & One time & 22 & 6.4 \\
mobile shopping & 2 times & 129 & 37.3 \\
& 3 times & 110 & 31.8 \\
& 4 times & 53 & 15.3 \\
& Over 4 times & 32 & 9.2 \\
\hline
\end{tabular}

\subsection{Measurement Items}

A pre-test and a pilot test were conducted to validate the measurement items. The pre-test involved four participants (two website designers and two mobile shoppers) who were familiar with mobile shopping. They were asked to provide comments while eliminating redundant or unrelated items. We invited 35 respondents to participate in the pilot test. Several minor modifications of the content and structure of the items were solicited before the formal application. The respondents were requested to rate each item on a seven-point Likert scale, on which a score of 1 means strongly disagree and 7 means strongly agree. Table 2 lists all of the questionnaire items and their supporting literature.

Table 2. Summary of measurement scales.

\begin{tabular}{llc}
\hline Construct & Measure & $\begin{array}{c}\text { Factor } \\
\text { loading }\end{array}$ \\
\hline $\begin{array}{l}\text { Navigability (NV) } \\
\text { Cronbach's Alpha }=0.88 ;\end{array}$ & \\
composite reliability $=0.90$ & \\
NV1 & $\begin{array}{l}\text { Wells et al. (2011) } \\
\text { During my last mobile purchase, using a } \\
\text { mobile device to navigate the coffee shop } \\
\text { website was easy for me }\end{array}$ & 0.89 \\
NV2 & $\begin{array}{l}\text { During my last mobile purchase, using a } \\
\text { mobile device to interact with the coffee } \\
\text { shop website was clear and understandable }\end{array}$ & 0.89 \\
\hline
\end{tabular}




\begin{tabular}{|c|c|c|}
\hline NV3 & $\begin{array}{l}\text { During my last mobile purchase, it was } \\
\text { easy for me to become a ubiquitous } \\
\text { shopper at navigating the pages of the } \\
\text { coffee shop website }\end{array}$ & 0.82 \\
\hline \multicolumn{3}{|c|}{ Information quality (IQ) } \\
\hline \multicolumn{3}{|c|}{$\begin{array}{l}\text { Cronbach's Alpha }=0.91 ; \\
\text { composite reliability }=0.90\end{array}$} \\
\hline & Pearson et al. (2012) & \\
\hline IQ1 & $\begin{array}{l}\text { During my last mobile purchase, the coffee } \\
\text { shop website provided me with } \\
\text { understandable product information }\end{array}$ & 0.86 \\
\hline IQ2 & $\begin{array}{l}\text { During my last mobile purchase, the coffee } \\
\text { shop website provided me with updated } \\
\text { product information }\end{array}$ & 0.86 \\
\hline IQ3 & $\begin{array}{l}\text { During my last mobile purchase, the coffee } \\
\text { shop website provided me with helpful } \\
\text { product information }\end{array}$ & 0.88 \\
\hline \multicolumn{3}{|c|}{ Security (SC) } \\
\hline \multicolumn{3}{|c|}{$\begin{array}{l}\text { Cronbach's Alpha }=0.94 \\
\text { composite reliability }=0.93\end{array}$} \\
\hline $\mathrm{SC} 1$ & $\begin{array}{l}\text { Wells et al. (2001) } \\
\text { I believe inappropriate parties cannot } \\
\text { deliberately intercept the information I } \\
\text { provided during my last mobile transaction } \\
\text { with the coffee shop website }\end{array}$ & 0.91 \\
\hline $\mathrm{SC} 2$ & $\begin{array}{l}\text { I believe that unauthorized parties will not } \\
\text { collect and store the personal information I } \\
\text { provided during my last mobile transaction } \\
\text { with the coffee shop website }\end{array}$ & 0.90 \\
\hline SC3 & $\begin{array}{l}\text { I believe that the coffee shop website will } \\
\text { not misuse my private information when I } \\
\text { make a mobile purchase }\end{array}$ & 0.90 \\
\hline \multicolumn{3}{|c|}{$\begin{array}{l}\text { Cronbach's Alpha }=0.92 ; \\
\text { composite reliability }=0.93\end{array}$} \\
\hline & Kleijnen $(2007)$ & \\
\hline TF1 & $\begin{array}{l}\text { During my last mobile purchase, coffee } \\
\text { shop website performed as well as it is } \\
\text { supposed to do. }\end{array}$ & 0.91 \\
\hline TF2 & $\begin{array}{l}\text { During my last mobile purchase, the coffee } \\
\text { shop website provided a dependable } \\
\text { service. }\end{array}$ & 0.91 \\
\hline TF3 & During my last mobile purchase, the coffee & 0.89 \\
\hline
\end{tabular}


shop website operation was reliable.

Visual appeal (VA)

Cronbach's Alpha $=0.93$;

composite reliability $=0.94$

Loiacono et al. (2007); Welles et al. (2001)

VA1

My last mobile visit to the coffee shop

website was visually pleasing

VA2

The coffee shop website provided a

visually appealing design during my last

mobile visit

VA3

The presentation of the coffee shop website

was appealing during my last mobile visit

Website reputation (WR)

Cronbach's Alpha $=0.89$;

composite reliability $=0.88$

Hansen et al. (2008)

WR1

During my last mobile purchase, I

compared coffee shop websites' images

before making a transaction

WR2

During my last mobile purchase, I used my mobile device to buy products from only coffee shop websites with good reputations.

WR3

During my last mobile purchase, the

reputation of the coffee shop website was recognizable

Perceived usefulness (PU)

Cronbach's Alpha $=0.90$;

composite reliability $=0.89$

Bhattacherjee (2001); Schierz et al. (2010)

PU1 Coffee shop mobile website enables me to

find a product quickly

PU2

Coffee shop mobile website enables me to

PU3

find a product ubiquitously

Overall, it is useful for me to conduct

Confirmation (CF)

purchases using my mobile device

Cronbach's Alpha $=0.88$;

composite reliability $=0.93$

Bhattacherjee (2001)

CF1

My experience with mobile purchasing was

better than what I expected

CF2

Using the mobile device to shop online

0.91 


\section{CF3}

Perceived value (PV)

Cronbach's Alpha $=0.87$;

composite reliability $=0.93$

Kuo et al. (2009); Lee et al. (2011)

PV1

PV2

PV3

Satisfaction (SAT)

It is valuable to my mobile purchases if the aesthetics of the coffee shop website are appealing

fitted well with my expectations

Overall, most of my expectations of mobile purchasing were confirmed

reputation of the coffee shop website is recognizable

Mobile shopping makes it valuable for me

to shop online anytime and anywhere

Cronbach's Alpha $=0.92$;

composite reliability $=0.92$

SAT1

SAT2

SAT3

Continuance intention

(CIT)

Cronbach's Alpha $=0.88$;

composite reliability $=0.87$

CIT1

CIT2

CIT3

Bhattacherjee (2001); Kuo et al. (2009)

I am satisfied with my experiences of

mobile purchasing

It is a good idea for me to make mobile $\quad 0.86$ purchases

Using my mobile device to shop online is a wise decision

Bhattacherjee (2001)

I intend to continue shopping on my

mobile device rather than discontinue this practice

My intention is to continue using my mobile device to shop online rather than use any alternative means

If I could, I would like to continue making mobile purchases in the future

\subsection{Reliability and Validity of Research Constructs}

Prior to formal analysis, preliminary data examination was conducted. We screened for missing data, outliers, construct reliability, and construct validity. No missing data or outliers were found. In order to evaluate 
construct reliability, this study assesses the Cronbach' $\alpha$ and composite reliabilities (CR) of all constructs. As shown in Table 2, all variables have both Cronbach' $\alpha$ and composite reliability values ranging from 0.87 to 0.94 , which exceed the reliability criterion of 0.7 , as suggested by researcher ${ }^{90}$; and all the average variance extracted (AVE) values (0.69-0.83) exceed the minimum level of 0.50 , as recommended by researchers ${ }^{86}$. Fornell and Larcker $^{86}$ suggest two criteria that should be met to establish convergent validity. First, all factor loadings should not only be significant but should also exceed 0.7. Second, the average variance extracted (AVE) for each construct should exceed the minimum level of 0.5 . All the items listed in Table 2 exhibit factor loadings greater than $0.70(0.79-0.93)$ and AVE of each constructs are more than $0.5(0.69-0.83)$ (see Table 3$)$. Thus, both criteria for convergent validity were met. Discriminant validity is the extent to which a construct and its indicator variables differ from another construct and its indicator variables ${ }^{87}$. We examined this using a criterion suggested by Fornell and Larcker ${ }^{86}$ : the square root of AVEs should be greater than the correlation between the two constructs. Table 3 shows that the correlation between the pair of constructs was less than the corresponding square root of AVEs (diagonal values). All the constructs met the requirement, providing evidence of discriminant validity.

Table 3. Correlations, CR and AVE.

\begin{tabular}{|c|c|c|c|c|c|c|c|c|c|c|c|c|c|}
\hline Construct & CR & AVE & NV & IQ & SC & TF & VA & WR & $\mathbf{P U}$ & $\mathbf{C F}$ & PV & SAT & CIT \\
\hline Navigability (NV) & 0.90 & 0.75 & 0.87 & & & & & & & & & & \\
\hline Information quality (IQ) & 0.90 & 0.74 & 0.45 & 0.86 & & & & & & & & & \\
\hline Security (SC) & 0.93 & 0.81 & 0.21 & 0.32 & 0.90 & & & & & & & & \\
\hline Transaction Fluency (TF) & 0.93 & 0.82 & -0.06 & -0.12 & -0.06 & 0.91 & & & & & & & \\
\hline Visual appeal (VA) & 0.94 & 0.83 & 0.36 & 0.48 & 0.22 & -0.04 & 0.91 & & & & & & \\
\hline Website reputation (WR) & 0.88 & 0.71 & 0.35 & 0.46 & 0.20 & -0.09 & 0.40 & 0.84 & & & & & \\
\hline Perceived usefulness (PU) & 0.89 & 0.74 & 0.30 & 0.41 & 0.14 & -0.04 & 0.34 & 0.38 & 0.86 & & & & \\
\hline Confirmation (CF) & 0.93 & 0.83 & 0.17 & 0.30 & 0.18 & -0.05 & 0.28 & 0.29 & 0.34 & 0.91 & & & \\
\hline Perceived value (PV) & 0.93 & 0.81 & 0.53 & 0.48 & 0.18 & -0.07 & 0.34 & 0.44 & 0.49 & 0.30 & 0.90 & & \\
\hline Satisfaction (SAT) & 0.92 & 0.79 & 0.30 & 0.38 & 0.20 & -0.10 & 0.35 & 0.38 & 0.52 & 0.50 & 0.52 & 0.89 & \\
\hline $\begin{array}{l}\text { Continuance intention } \\
\text { (CIT) }\end{array}$ & 0.87 & 0.69 & 0.24 & 0.29 & 0.14 & -0.05 & 0.34 & 0.27 & 0.48 & 0.41 & 0.49 & 0.59 & 0.83 \\
\hline
\end{tabular}

Note: Diagonal elements in the 'correlation of constructs' matrix are the square root of the average variance extracted (AVE) 


\subsection{PLS analysis}

For data analysis purposes, we applied partial least squares (PLS) method. PLS allows researchers to name the relationships among various factors and the measures underlying each construct ${ }^{88}$. PLS enables us to simultaneously evaluate model parameters and structural path coefficient ${ }^{89,90}$. In comparison to LISREL, PLS is a prediction-based, data-analytic method, which comprises an explanatory capacity based on maximizing the variance explained in the constructs rather than the model fitness ${ }^{89}$. Thus, PLS is an appropriate statistical analysis tool for this study.

As mentioned in Section 2.2., consumers with different shopping orientations behave differently on a coffee shop website, making it is necessary for coffee shop owners to identify which website construct warrants the strongest impact on the nature of the shopping orientations being performed by mobile shoppers. Consistent with Okada ${ }^{91}$, we categorize our respondents into three oriented groups based on their average ratings of perceived usefulness and perceived value. Following previous body of research ${ }^{28,31,32,91}$, we regrouped our sample into three segments: utilitarian, hedonic and intermediate using perceived usefulness and perceived value as regrouping criteria of the sample.

Respondents who rated higher perceived usefulness than perceived value are categorized into the utilitarian-oriented group, while respondents who rated perceived usefulness lower than perceived value are categorized into the hedonic-oriented group. The intermediate group is made up of respondents whose average ratings of perceived usefulness are equal to their average ratings of perceived value. As shown in Figures 3A, 3B, 3C and Tables 4A, 4B, 4C, the results show PLS analysis for the three oriented groups. In sum, these factors explain at least $61 \%$ of the variance of continuance intention for the three oriented groups. We explain the results in detail as follows:

\section{Utilitarian-oriented group}

Structural (security, $\beta=0.43 \mathrm{t}=5.31$; transaction fluency, $\beta=-0.26 \mathrm{t}=2.62$ ) and functional (navigability, $\beta=0.28 \mathrm{t}=2.11$; information quality, $\beta=0.29$ $\mathrm{t}=2.26$ ) constructs exerted their influences on confirmation and perceived usefulness respectively in the utilitarian-oriented group. We found a two-way influence of confirmation on perceived usefulness $(\beta=0.25, \mathrm{t}=1.89)$ and satisfaction $(\beta=0.55, \mathrm{t}=7.56)$ for the utilitarian-oriented group. The direct effects of perceived usefulness on satisfaction $(\beta=0.33, t=3.57)$ and 
continuance intention $(\beta=0.14, \mathrm{t}=2.11)$ were significantly found in the utilitarian-oriented group but not in the hedonic-oriented group.

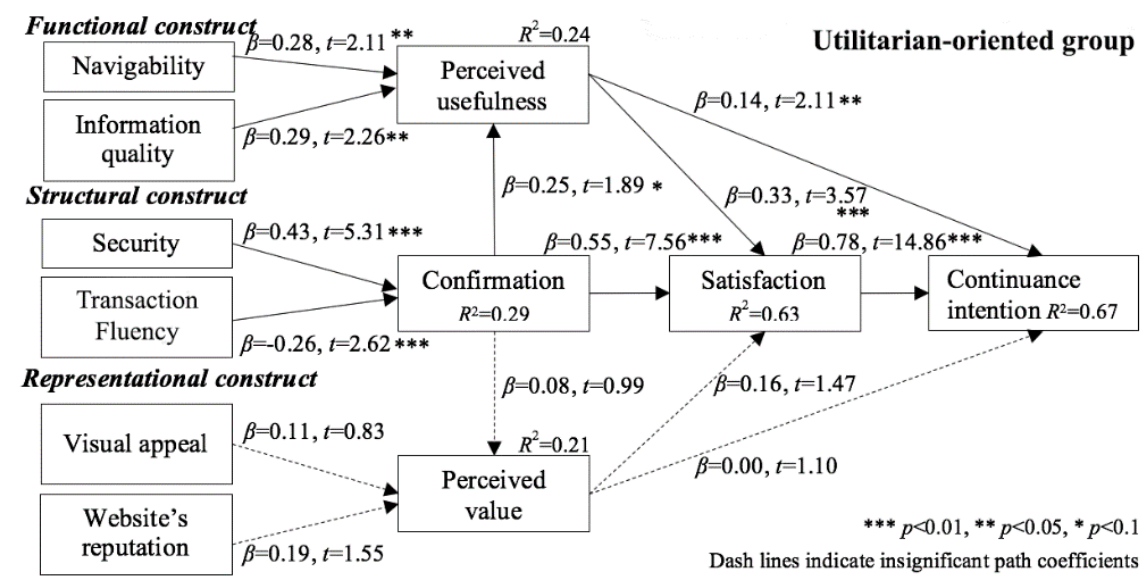

Figure 3A. PLS analysis of utilitarian-oriented group.

Table 4A. Tests of Hypothesized Relationships for Utility-oriented Group

\begin{tabular}{llcl}
\hline \multicolumn{1}{c}{ Hypothesis } & Path Coefficient & t-value & \multicolumn{1}{c}{ Decision } \\
Security $\rightarrow$ Confirmation & $0.43^{* * *}$ & 5.31 & H1 (supported) \\
Transaction Fluency $\rightarrow$ Confirmation & $-0.26^{* * *}$ & 2.62 & H2 (supported) \\
Navigability $\rightarrow$ Perceived Usefulness & $0.28^{* *}$ & 2.11 & H3 (supported) \\
Information Quality $\rightarrow$ Perceived Usefulness & $0.29^{* *}$ & 2.26 & H4 (supported) \\
Visual Appeal $\rightarrow$ Perceived Value & 0.11 & 0.83 & H5 (not supported) \\
Website Reputation $\rightarrow$ Perceived Value & 0.19 & 1.55 & H6 (not supported) \\
Confirmation $\rightarrow$ Perceived Usefulness & $0.25^{*}$ & 1.89 & H7 (supported) \\
Confirmation $\rightarrow$ Satisfaction & $0.55^{* * *}$ & 7.56 & H8 (supported) \\
Perceived Usefulness $\rightarrow$ Satisfaction & $0.33^{* * *}$ & 3.57 & H9 (supported) \\
Perceived Usefulness $\rightarrow$ Continuance Intention & $0.14^{* *}$ & 2.11 & H10 (supported) \\
Satisfaction $\rightarrow$ Continuance Intention & $0.78^{* * *}$ & 14.86 & H11 (supported) \\
Confirmation $\rightarrow$ Perceived Value & 0.08 & 0.99 & H12 (not supported) \\
Perceived Value $\rightarrow$ Satisfaction & 0.16 & 1.47 & H13 (not supported) \\
Perceived Value $\rightarrow$ Continuance Intention & 0.00 & 1.10 & H14 (not supported) \\
\hline
\end{tabular}

Notes: *** $\mathrm{P}<0.01,{ }^{* *} \mathrm{P}<0.05,{ }^{*} \mathrm{P}<0.10$. 


\section{Hedonic-oriented group}

Structural (security, $\beta=0.31 \mathrm{t}=3.31$; transaction fluency, $\beta=-0.15 \mathrm{t}=1.38$ ) and representational (visual appeal, $\beta=0.29 \mathrm{t}=3.01$; website reputation, $\beta=0.19 \mathrm{t}=2.96)$ constructs significantly affect confirmation and perceived value in only the hedonic-oriented group with the exception of transaction fluency. We found a two-way influence of confirmation on perceived value $(\beta=0.35, \mathrm{t}=4.72)$ and satisfaction $(\beta=0.23, \mathrm{t}=3.18)$. The direct effects of perceived value were found to significantly affect satisfaction $(\beta=0.61$, $\mathrm{t}=9.48)$ and continuance intention $(\beta=0.46, \mathrm{t}=4.85)$ only in the hedonic-oriented group but not in the utilitarian-oriented group.

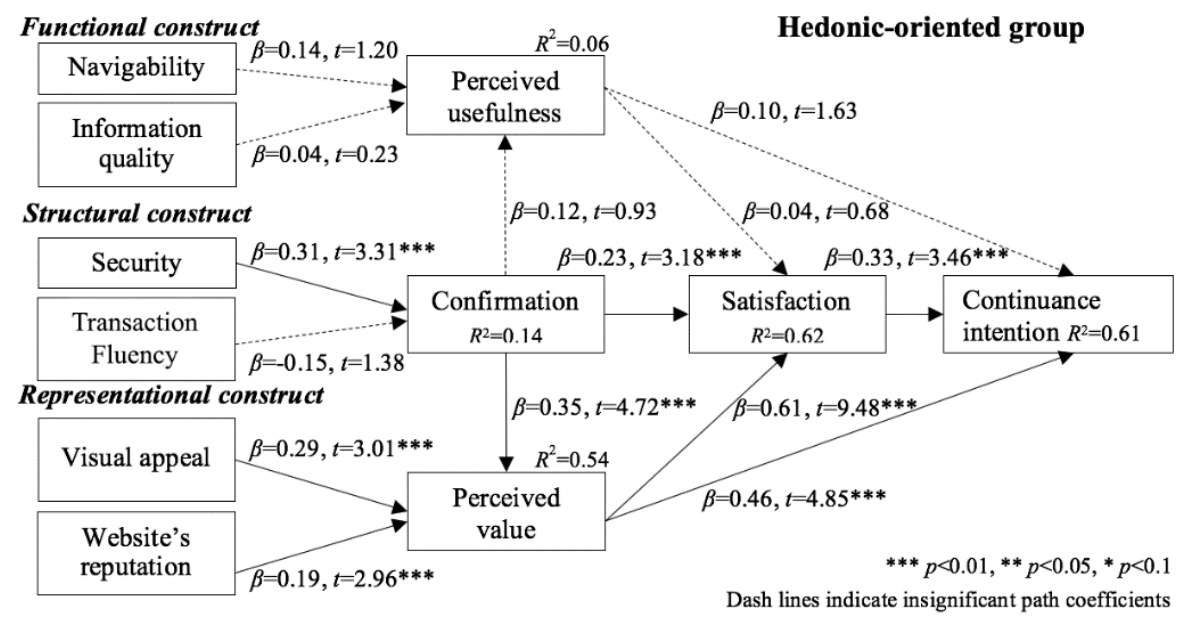

Figure 3B. PLS analysis of hedonic-oriented group.

Table 4B. Tests of Hypothesized Relationships for Hedonic-oriented Group

\begin{tabular}{llcl}
\hline \multicolumn{1}{c}{ Hypothesis } & Path Coefficient & t-value & \multicolumn{1}{c}{ Decision } \\
Security $\rightarrow$ Confirmation & $0.31^{* * *}$ & 3.31 & H1 (supported) \\
Transaction Fluency $\rightarrow$ Confirmation & -0.15 & 1.38 & H2 (not supported) \\
Navigability $\rightarrow$ Perceived Usefulness & 0.14 & 1.20 & H3 (not supported) \\
Information Quality $\rightarrow$ Perceived Usefulness & 0.04 & 0.23 & H4 (not supported) \\
Visual Appeal $\rightarrow$ Perceived Value & $0.29^{* * *}$ & 3.01 & H5 (supported) \\
Website Reputation $\rightarrow$ Perceived Value & $0.19^{* * *}$ & 2.96 & H6 (supported) \\
Confirmation $\rightarrow$ Perceived Usefulness & 0.12 & 0.93 & H7 (not supported) \\
Confirmation $\rightarrow$ Satisfaction & $0.23^{* * *}$ & 3.18 & H8 (supported) \\
Perceived Usefulness $\rightarrow$ Satisfaction & 0.04 & 0.68 & H9 (not supported)
\end{tabular}




$\begin{array}{llll}\text { Perceived Usefulness } \rightarrow \text { Continuance Intention } & 0.10 & 1.63 & \text { H10 (not supported) } \\ \text { Satisfaction } \rightarrow \text { Continuance Intention } & 0.33^{* * *} & 3.46 & \text { H11 (supported) } \\ \text { Confirmation } \rightarrow \text { Perceived Value } & 0.35^{* * *} & 4.72 & \text { H12 (supported) } \\ \text { Perceived Value } \rightarrow \text { Satisfaction } & 0.61^{* * *} & 9.48 & \text { H13 (supported) } \\ \text { Perceived Value } \rightarrow \text { Continuance Intention } & 0.46^{* * *} & 4.85 & \text { H14 (supported) }\end{array}$

Notes: *** $\mathrm{P}<0.01, * * \mathrm{P}<0.05, * \mathrm{P}<0.10$.

\section{Intermediate group}

Structural (security, $\beta=0.39 \mathrm{t}=4.18$; transaction fluency, $\beta=-0.22$ $\mathrm{t}=2.23$ ), functional (navigability, $\beta=0.38 \mathrm{t}=3.17$; information quality, $\beta=0.30$ $\mathrm{t}=2.23$ ) and representational constructs (visual appeal, $\beta=0.19 \mathrm{t}=1.80$; website reputation, $\beta=0.53 \mathrm{t}=4.63$ ) were all found to significantly affect confirmation, perceived usefulness, and perceived value in the intermediate group. On the other hand, the three-way influence of confirmation on perceived usefulness $(\beta=0.27, \mathrm{t}=3.62)$, satisfaction $(\beta=0.61, \mathrm{t}=8.96)$ and perceived value $(\beta=0.19, \mathrm{t}=2.19)$ was identified in the intermediate group.

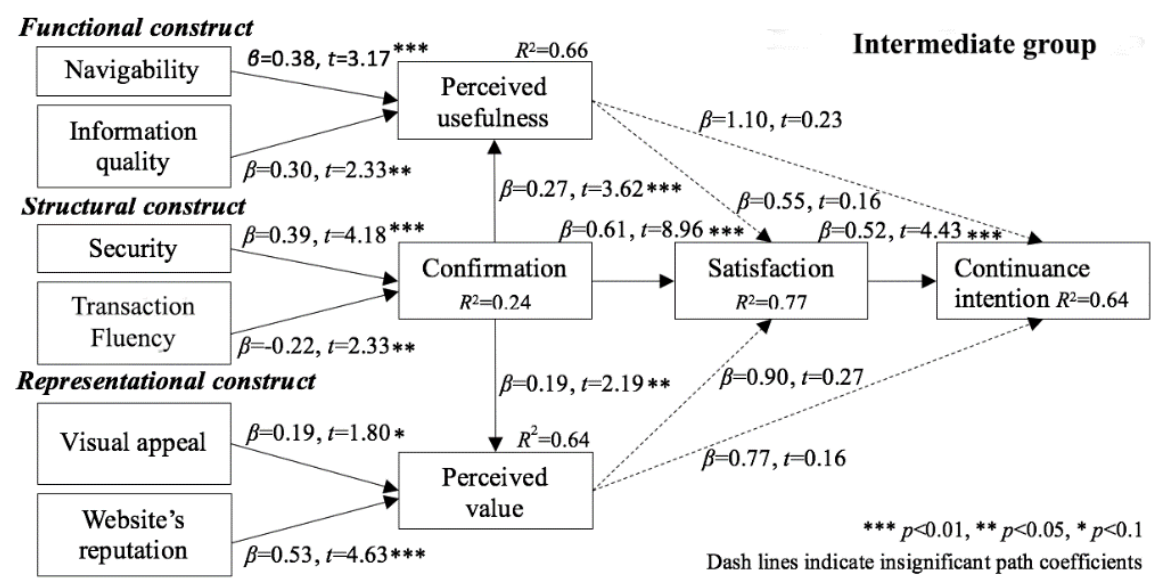

Figure 3C. PLS analysis of intermediate group. 
Table 4C. Tests of Hypothesized Relationships for Intermediate Group

\begin{tabular}{llll}
\hline \multicolumn{1}{c}{ Hypothesis } & Path Coefficient & t-value & Decision \\
Security $\rightarrow$ Confirmation & $0.39^{* * *}$ & 4.18 & H1 (supported) \\
Transaction Fluency $\rightarrow$ Confirmation & $-0.22^{* *}$ & 2.33 & H2 (supported) \\
Navigability $\rightarrow$ Perceived Usefulness & $0.38^{* * *}$ & 3.17 & H3 (supported) \\
Information Quality $\rightarrow$ Perceived Usefulness & $0.30^{* *}$ & 2.33 & H4 (supported) \\
Visual Appeal $\rightarrow$ Perceived Value & $0.19^{*}$ & 1.80 & H5 (supported) \\
Website Reputation $\rightarrow$ Perceived Value & $0.53^{* * *}$ & 4.63 & H6 (supported) \\
Confirmation $\rightarrow$ Perceived Usefulness & $0.27^{* * *}$ & 3.62 & H7 (supported) \\
Confirmation $\rightarrow$ Satisfaction & $0.61^{* * *}$ & 8.96 & H8 (supported) \\
Perceived Usefulness $\rightarrow$ Satisfaction & 0.55 & 0.16 & H9 (not supported) \\
Perceived Usefulness $\rightarrow$ Continuance Intention & 1.10 & 0.23 & H10 (not supported) \\
Satisfaction $\rightarrow$ Continuance Intention & $0.52^{* * *}$ & 4.43 & H11 (supported) \\
Confirmation $\rightarrow$ Perceived Value & $0.19^{* *}$ & 2.19 & H12 (supported) \\
Perceived Value $\rightarrow$ Satisfaction & 0.90 & 0.27 & H13 (not supported) \\
Perceived Value $\rightarrow$ Continuance Intention & 0.77 & 0.16 & H14 (not supported) \\
\hline
\end{tabular}

Notes: *** $\mathrm{P}<0.01, * * \mathrm{P}<0.05, * \mathrm{P}<0.10$.

\section{DISCUSSION}

\subsection{Intolerable Website Constructs in the Intermediate Group}

Structural, functional, and representational constructs were all found to affect confirmation, perceived usefulness, and perceived value in the intermediate group, while perceived usefulness and perceived value affect neither satisfaction nor continuance intention. This implies that mobile shoppers in this group do not rely on post-expectation factors (e.g., perceived usefulness, perceived value) to promote mobile shopping continuance, instead, they rely on confirmation each time that they conduct a mobile visit to the coffee shop website. As a result, mobile shoppers in this group belong to both utilitarian and hedonic orientations and their orientation is changeable because their dual shopping orientation could adjust into a single orientation when they visit the same coffee shop website next time. 


\subsection{Tolerable Website Constructs in The Utilitarian-Oriented Group}

Structural and functional constructs were found to affect confirmation and perceived usefulness in utilitarian-oriented group, whereas the representational construct exerted no significant effect on perceived value. Perceived usefulness in this group was found to significantly affect both satisfaction and continuance intention but perceived value did not. Indeed, utilitarian-oriented mobile shoppers focus primarily on the utility aspects of mobile shopping and therefore pay particular attention to the performance of the functional and structural constructs. Apparently, the structural construct is required to support those factors (e.g., security, transaction fluency) related to the operation of the coffee shop website, while factors (e.g., navigability, information quality) related to the functional construct serve as facilitators that fulfill the needs of mobile shoppers with utilitarian shopping orientations. The need fulfillment here in turn leads to mobile shopping satisfaction and continuance intention. For example, a mobile shopper with a utilitarian shopping orientation may consider whether she is able to smoothly find complete product information on the coffee shop website, and may also care about whether the transaction on the website site can proceed without waiting for a long time and worrying about security threats. If all these concerns are addressed by the functional and structural constructs, then she will perceive usefulness and confirmation of her mobile transaction, which jointly lead to mobile shopping satisfaction and continuance intention. Therefore, mobile shoppers in this case will only tolerate the underperformance of the representational construct but are unlikely to compromise on the performance of the functional and structural constructs that are decisive to their utilitarian shopping needs.

\subsection{Tolerable Website Constructs in The Hedonic-Oriented Group}

Structural and representational constructs were found to affect confirmation and perceived value in the hedonic-oriented group, whereas the functional construct exerted no significant effect on perceived usefulness. Contrary to the utilitarian-oriented group, perceived value in this group was found to significantly affect both satisfaction and continuance intention but perceived usefulness did not. As a result, hedonic-oriented mobile shoppers focus primarily on aesthetic presentations of the coffee shop website and place more emphasis on representational and structural constructs than on the functional construct. Consequently, the factors of structural construct (e.g., security) are most basic in the support of the operations of the coffee 
shop website, similar to the utilitarian-oriented group. However, the factors of representational construct (e.g., visual appeal, website's reputation) pertain to factors complying with the needs of mobile shoppers with hedonic shopping orientations. Another notable finding in this group is that transaction fluency did not significantly affect confirmation. A feasible explanation is that the more aesthetic elements the website presents, the more broadband is required resulting in longer download time.

\section{CONCLUSION}

\subsection{Theoretical contribution}

The current study contributes to the growing literature concerning mobile shopping continuance intention from a coffee industry perspective. Several theoretical contributions drawn from this study are as follows: First, unlike previous studies ${ }^{10,40}$ that vaguely stated that the effects of any pre-acceptance variables of an information system are captured within the confirmation construct of ECM. This study demonstrates that the three proposed website constructs (e.g. structural, functional, and representational) are the most important pre-acceptance variables antecedent to consumers' confirmation of mobile shopping continuance. Although current research focused on coffee shop online stores, the three website constructs are considered to be generalizable to any mobile shopping website; Second, prior studies dealing with mobile shopping continuance have treated mobile shoppers as the same regardless of their varying shopping orientations ${ }^{92,93}$. Our findings provide empirical evidence that mobile shoppers have different shopping orientations and they behave differently depending on these orientations. This implies behavior instability since mobile shoppers may be utilitarian-oriented once they visit a shopping website but they can also be hedonic-oriented during their next journey to the same shopping website. Finally, the current study demonstrates that the zone of tolerance can be fortified by categorizing mobile shoppers with different shopping orientations to further our understanding of mobile shopping continuance. Mobile shoppers with a utilitarian shopping orientation prioritize both structural and functional website constructs but tolerate the performance of representational aspects presented by the shopping website, whereas mobile shoppers with a hedonic shopping orientation prioritize structural and representational website constructs but tolerate the performance of functional aspects of the shopping website. Mobile shoppers with both utilitarian and hedonic shopping orientations are not intolerant of website constructs at all. 


\subsection{Practical implications}

Our study has several managerial implications. First, the findings reveal that mobile shoppers with different shopping orientations behave differently when visiting coffee shop websites. Proprietors of coffee shops are therefore suggested to treat their mobile shoppers unequally based on their respective shopping orientations. However, coffee shop websites currently pay scant attention to the orientation-specific design features targeting mobile shoppers with different shopping needs. Shopping orientations are hard to discern unless consumers are willing to provide certain information. The current study suggests a viable way to ascertain this information: (1) providing a simple questionnaire that requests mobile shoppers to state their shopping orientations before getting onto the website. Example questions may include "do you want us to help you quickly find the most popular product", or "do you want to patronize the website without having our product recommendation during the visit". The answer to the first question helps to identify a utilitarian shopping orientation, while a hedonic shopping orientation can be elicited from the answer to the second question. (2) Directing mobile shoppers into an orientation-specific website that suits their stated shopping orientation. The manner we suggest above is quite necessary, because one is unlikely to design a shopping website that takes all kinds of shopping needs into account ${ }^{94}$.

Second, as the available budget and resources might be scarce, coffee shop proprietors should carefully allocate their resources. The findings of the current study show that mobiles shoppers with different shopping orientations will tolerate the performance of the coffee shop website construct which is irrelevant to their shopping orientations. Thus, we suggest that proprietors should rather allocate their finite resources to the website constructs that are intolerable by mobile shoppers and allocate relatively lower resources to the ones that are tolerable.

Finally, the analysis reveals that the structural construct is the only significant website construct found in all three orientation groups. This finding indicates that the structural construct needs to be particularly maintained regardless of different shopping orientations. Inarguably, mobile shoppers should hesitate to revisit a shopping website if the security of that website is inferior and if the transaction fluency of that website is severe. In other words, the structural construct is a must-have factor that makes a shopping website workable and its absence leads to discontinued website visits $^{95}$. 


\section{REFERENCES}

[1] S. Joseph, Starbucks to put 'ecommerce on steroids' with mobile delivery service. Marketing Week (Online Edition), p. 1-1, 2014.

[2] L. Roderick, Nescafé goes after millennials as it becomes first global brand to move online presence to Tumblr. Marketing Week (Online Edition), p. 1-1, 2015.

[3] L. Ping, and $\mathrm{H}$. Wu, Research on the E-commerce Operation Performance of SMEs based on Cloud Computing Service Platform. Revista de la Facultad de Ingenieria, 32(3), 500-509, 2017.

[4] C.K. Coursaris, and D.J. Kim, A meta-analytical review of empirical mobile usability studies. Journal of usability studies, 6(3), 117-171, 2011.

[5] A. Tom, R. A. M. Sangadi, and L. Ament, Retailers Need to Adapt to the Smart Customer: Smartphone-wielding customers are reshaping the shopping experience, both online and in-store. CRM Magazine, 21(12), 38-39, 2017.

[6] EMarketer. New eMarketer Forecast Sees Mobile Driving Retail Ecommerce in China. 2017.

[7] C. Gan, and H. Li, Understanding the effects of gratifications on the continuance intention to use WeChat in China: A perspective on uses and gratifications. Computers in Human Behavior, 78, 306-315, 2018. http://dx.doi.org/10.1016/j.chb.2017.10.003

[8] K. Yang, Determinants of US consumer mobile shopping services adoption: implications for designing mobile shopping services. Journal of Consumer Marketing, 27(3), 262-270, 2010. http://dx.doi.org/10.1108/07363761011038338

[9] K. Yang, and H.-Y. Kim, Mobile shopping motivation: an application of multiple discriminant analysis. International Journal of Retail \& Distribution Management, 40(10), 778-789, 2012. http://dx.doi.org/10.1108/09590551211263182

[10] A. Bhattacherjee, Understanding Information Systems Continuance: an Expectation-confirmation Model. MIS Quarterly, 25 (3), 351-370, 2001. http://dx.doi.org/10.2307/3250921

[11] B. Hadji, and P. Degoulet, Information system end-user satisfaction and continuance intention: A unified modeling approach. Journal of Biomedical Informatics, 61, 185-193, 2016.

[12] M.-C. Lee, Explaining and predicting users' continuance intention toward e-learning: An extension of the expectation-confirmation model. Computers \& Education, 54(2), 506-516, 2010.

[13] Y. Lee, and O. Kwon, Intimacy, familiarity and continuance intention: An extended expectation-confirmation model in web-based services. 
Electronic Commerce Research and Applications, 10(3), 342-357, 2011. http://dx.doi.org/10.1016/j.elerap.2010.11.005

[14] T.-C. Lin, The integration of value-based adoption and expectationconfirmation models: An example of IPTV continuance intention. Decision Support Systems, 54(1), 63-75, 2012.

[15] C. Dalsang, C. S. Gi, and C. H. Yeon, Empirical Study On Determinants For The Continued Use Of Mobile Shopping Apps. Issues in Information Systems, 17(2), 34, 2016.

[16] J. Kim, J. Lee, K. Han, and M. Lee, Business as Buildings: Metrics for the Architectural Quality of Internet Business. Information Systems Research, 13(3), 239-254, 2002.

[17] J. A. Miller, Exploring Satisfaction, Modifying Models, Eliciting Expectations, Posing Problems and Making Meaningful Measurements. In H. K. Hunt (Ed.) Conceptualization and Measurement of Consumer Satisfaction and Dissatisfaction, Cambridge, Massachusetts: Marketing Science Institute, 1997.

[18] M. Wolfinbarger and M. Gilly, Shopping Online for Freedom, Control, and Fun. California Management Review 43(2), 34-55, 2001. http://dx.doi.org/10.2307/41166074

[19] T. L. Keiningham, M. K. Goddard, T. G. Vavra, \& A. J. Iaci, Customer Delight and The Bottom Line, American Marketing Association, 1999.

[20] A. Parasuraman, V.A. Zethhaml, and L.L. Berry, Alternative scales for measuring service quality: a comparative assessment based on psychometric and diagnostic criteria, Elsevier Advanced Technology Publications, 201, 1994. http://dx.doi.org/10.1016/0022-4359(94)90033-7

[21] M. M. Kevin and B. Terri Feldman, I love my accountants - they're wonderful: understanding customer delight in the professional services arena. Journal of Services Marketing, 3,152, 2006.

[22] T. Strandvik, Tolerance zones in perceived service quality. Helsingfors: Swedish School of Economics and Business Administration, 1994.

[23] W. H. DeLone and E.R. McLean, Information systems success: The quest for the dependent variable. Information systems research, 3(1), 60-95, 1992. http://dx.doi.org/10.1287/isre.3.1.60

[24] P. Zhang and G. M. von Dran, User Expectations and Rankings of Quality Factors in Different Web Site Domains. International Journal of Electronic Commerce, 6 (2), 9-33, 2002.

[25] C.-T. Chang and Z.-H. Cheng, Tugging on Heartstrings: Shopping Orientation, Mindset, and Consumer Responses to Cause-Related Marketing, 337-350, 2015.

[26] D. Scarpi, Work and fun on the internet: the effects of utilitarianism and hedonism online. Journal of interactive marketing, 26(1), 53-67, 
2012. http://dx.doi.org/10.1016/j.intmar.2011.08.001

[27] M.-C. Cervellon, J. Sylvie, and P.-V. Ngobo, Shopping orientations as antecedents to channel choice in the French grocery multichannel landscape. Journal of Retailing and Consumer Services, 27, 31-51, 2015. http://dx.doi.org/10.1016/j.jretconser.2015.06.008

[28] B. J. Babin, W. R. Darden, and M. Griffin, Work and/or Fun: Measuring Hedonic and Utilitarian Shopping Value. Journal of Consumer Research, 20 (4), 644-656, 1994. http://dx.doi.org/10.1086/209376

[29] V. D. Kaltcheva, and B. A. Weitz, When Should a retailer create an exciting store environment? Journal of Marketing, 70(1), 107-118, 2006.

[30] X. Wu, Q. Chen, W. Zhou, and J. Guo, A Review of Mobile Commerce Consumers' Behavior Research: Consumer Acceptance, Loyalty and Continuance (2000-2009). International Journal of Mobile Communications, 8(5), 528-560, 2010.

[31] J. Wu and X. Lu, Effects of Extrinsic and Intrinsic Motivators on Using Utilitarian, Hedonic, and Dual-purposed Information Systems: a Meta-analysis. Journal of the Association for Information Systems 14(3), 153-191, 2013.

[32] C. Mathwick, N. K. Malhotra, and E. Rigdon, The Effect of Dynamic Retail Experiences on Experiential Perceptions of Value: An Internet and Catalog Comparison. Journal of Retailing, 78(1), 51-60, 2002.

[33] M. Groß, Impediments to mobile shopping continued usage intention: A trust-risk-relationship. Journal of Retailing and Consumer Services, 33, 109-119, 2016.

[34] M. Kleijnen, K. de Ruyter, and M. Wetzels, An assessment of value creation in mobile service delivery and the moderating role of time consciousness. Journal of Retailing, 83(1), 33-46, 2007. http://dx.doi.org/10.1016/j.jretai.2006.10.004

[35] F. D. Davis, Perceived Usefulness, Perceived Ease of Use, and User Acceptance of Information Technology. MIS Quarterly, 13(3), 319-340, 1989. http://dx.doi.org/10.2307/249008

[36] A. P. Oghuma, C. F. Libaque-Saenz, S. F. Wong, and Y. Chang, An expectation-confirmation model of continuance intention to use mobile instant messaging. Telematics and Informatics, 33(1), 34-47, 2016. http://dx.doi.org/10.1016/j.tele.2015.05.006

[37] C.-L. Hsu, and J.C.-C. Lin, What drives purchase intention for paid mobile apps? - An expectation confirmation model with perceived value. Electronic Commerce Research and Applications, 14(1), 46-57, 2015. http://dx.doi.org/10.1016/j.elerap.2014.11.003

[38] J. Y. L. Thong, S. J. Hong, and K. Y. Tam, The Effects of Post-adoption 
Beliefs on the Expectation-confirmation Model for Information Technology Continuance. International Journal of Human-Computer $\begin{array}{llll}\text { Studies, } & 64 & \text { (9), } & 799-810,\end{array}$ http://dx.doi.org/10.1016/j.ijhcs.2006.05.001

[39] Y. Lee and O. Kwon, Intimacy, Familiarity and Continuance Intention: an Extended Expectation-confirmation Model in Web-based Services. Electronic Commerce Research and Applications, 10(3), 342-357, 2011. http://dx.doi.org/10.1016/j.elerap.2010.11.005

[40] C. S Lin, S. Wu, and R. J. Tsai, Integrating Perceived Playfulness into Expectation-confirmation Model for Web Portal Context. Information \& Management 42 (5), 683-693, 2005.

[41] D. Y. Cho, H. J. Kwon, and H. Y. Lee, Analysis of Trust in Internet and Mobile Commerce Adoption. Paper presented at the annual meeting for the Hawaii International Conference on System Sciences 40th, Waikoloa, January 3-6, 2007.

[42] S. Yang, Y. Chen, and J. Wei, Understanding Consumers' Web-Mobile Shopping Extension Behavior: A Trust Transfer Perspective. Journal of Computer Information Systems, 55(2), 78-87, 2015. http://dx.doi.org/10.1080/08874417.2015.11645759

[43] M. Khalifa, M. and N.K. Shen, Explaining the adoption of transactional B2C mobile commerce. Journal of Enterprise Information Management, 21(2), 110-124, 2008. http://dx.doi.org/10.1108/17410390810851372

[44] M.S. Featherman, and P.A. Pavlou, Predicting e-services adoption: a perceived risk facets perspective. International Journal of Human Computer Studies, 59, 451-474, 2003. http://dx.doi.org/10.1016/S1071-5819(03)00111-3

[45] M. Hubert, M. Blut, C. Brock, C. Backhaus and T. Eberhardt, Acceptance of Smartphone-Based Mobile Shopping: Mobile Benefits, Customer Characteristics, Perceived Risks, and the Impact of Application Context. Psychology \& Marketing, 34(2), 175-194, 2017. http://dx.doi.org/10.1002/mar.20982

[46] R. L. Oliver, A Cognitive Model of the Antecedents and Consequences of Satisfaction Decisions. Journal of Marketing Research, 17 (4), 460-469, 1980. http://dx.doi.org/10.1177/002224378001700405

[47] F. Ferri, P. Grifoni, and T. Guzzo, Factors determining mobile shopping. A theoretical model of mobile commerce acceptance. International Journal of Information Processing and Management (IJIPM), 4(7), 89-101, 2013.

[48] Q. Yang, C. Pang, L. Liu, D. C. Yen and M. J. Tarn, Exploring consumer perceived risk and trust for online payments: An empirical study in China's younger generation. Computers in Human Behavior, 
50, 9-24, 2015. http://dx.doi.org/10.1016/j.chb.2015.03.058

[49] K.-K. Lai, X. Chong, J. Zhang, and L. Nie, An empirical analysis of mobile internet acceptance from a value-based view. International Journal of Mobile Communications, 10(5), 536-557, 2012.

[50] A. M. Aladwani, The Development of Two Tools for Measuring the Easiness and Usefulness of Transactional Web Sites. European Journal of Information Systems, 11(3), 223-234, 2002. http://dx.doi.org/10.1057/palgrave.ejis.3000432

[51] Z. Yang, R. T. Peterson, and S. Cai, Service Quality Dimensions of Internet Retailing: An Exploratory Analysis. Journal of Service Marketing, 17(7), 685-700, 2003. http://dx.doi.org/10.1108/08876040310501241

[52] K. Fitzgerald, Citi Learns Simplicity Is Critical in Mobile Wallets. American Banker, 177(F317), 15-15, 2012.

[53] C. McKelvey, Tariff simplicity key to switch on mobile user interest. Precision Marketing, 18(35), 12-12, 2006.

[54] V. A. Zeithaml, A. Parasuraman, and A. Malhotra, Service Quality Delivery through Web Sites: A Critical Review of Extant Knowledge. Journal of the Academy of Marketing Science, 30(4), 362-375, 2002. http://dx.doi.org/10.1177/009207002236911

[55] P. Spenner, and K. Freeman, To keep your customers, keep it simple: they don't want a 'relationship' with you. Just help them make good choices. Harvard Business Review, (5), 108, 2012.

[56] B. H. Wixom, and P. A. Todd, A Theoretical Integration of User Satisfaction and Technology Acceptance. Information Systems Research, 16(1), 85-102, 2005. http://dx.doi.org/10.1287/isre.1050.0042

[57] Y.-F. Chen, and Y.-C. Lan, An empirical study of the factors affecting mobile shopping in Taiwan. International Journal of Technology and Human Interaction (IJTHI), 10(1), 19-30, 2014. http://dx.doi.org/10.4018/ijthi.2014010102

[58] H.H. Chang, K.H. Wong, and S.Y. Li, Applying push-pull-mooring to investigate channel switching behaviors: M-shopping self-efficacy and switching costs as moderators. Electronic Commerce Research and Applications, 24, 50-67, 2017. http://dx.doi.org/10.1016/j.elerap.2017.06.002

[59] S.-P. Jeng, Online gift-searching: gift-giving orientations and perceived benefits of searching. Online Information Review, 37(5), 771-786, 2013. http://dx.doi.org/10.1108/OIR-05-2012-0093

[60] S. Okazaki, and F. Mendez, Perceived Ubiquity in Mobile Services. Journal of Interactive Marketing, 27(2), 98-111, 2013. http://dx.doi.org/10.1016/j.intmar.2012.10.001 
[61] W. H. Delone, and E. R. McLean. The DeLone and McLean model of information systems success: a ten-year update. Journal of management information systems, 19(4), 9-30, 2003.

[62] T. Ahn, S. Ryu, and I. Han, The Impact of the Online and Offline Features on the User Acceptance of Internet Shopping Malls. Electronic Commerce Research and Applications, 3(4), 405-420, 2004. http://dx.doi.org/10.1016/j.elerap.2004.05.001

[63] B.Xiao and I. Benbasat, E-commerce Product Recommendation Agents: Use, Characteristics, and Impact. MIS Quarterly, 31(1), 137-209, 2007. http://dx.doi.org/10.2307/25148784

[64] N. Bahatti, A. Bouch, and A. Kuchinsky, Integrating User-perceived Quality Into Web Server Design. Computer Networks, 33(1-6), 1-16, 2000.

[65] A. Rai, S. S. Lang, and R. B. Welker, Assessing the Validity of IS Success Models: an Empirical Test and Theoretical Analysis. Information Systems Research, 13(1), 50-69, 2002. http://dx.doi.org/10.1287/isre.13.1.50.96

[66] P. Seddon, and M. Y. Kiew, A Partial Test and Development of DeLone and McLean's Model of IS Success. Australasian Journal of Information Systems, 4(1), 90-106, 1996.

[67] C. Mathwick, N. K. Malhotra, and E. Rigdon, Experience Value: Conceptualization, Measurement and Application in the Catalog and Internet Shopping Environment. Journal of Retailing, 77 (1), 39-56, 2001.

[68] M. B. Holbrook, The Nature of Customer Value: an Axiology of Services in the Consumption Experience. In T. R. Roland and L. O. Richard (Ed.) Service Quality: New Directions in Theory and Practice, 21-71. Newbury Park, California: Sage, 1994. http://dx.doi.org/10.4135/9781452229102.n2

[69] C. Driefus, Talking Shop: A Conversation with the Men Who Brought You Neiman Marcus, Ikea and Virgin. The New York Times Magazine, 82-86, 1997.

[70] W.Y. Liang, The Adaptation of a Post-Acceptance Model for Information System Continuance in Recommender Systems. in 2017 6th IIAI International Congress on Advanced Applied Informatics (IIAI-AAI). 2017. http://dx.doi.org/10.1109/IIAI-AAI.2017.147

[71] G. W. Tan and K. K. Wei, An Empirical Study of Web Browsing Behavior: towards an Effective Website Design. Electronic Commerce Research and Applications, 5(4), 261-271, 2006.

[72] K.-L. Hsiao, and C.-C. Chen, What drives in-app purchase intention for mobile games? An examination of perceived values and loyalty. Electronic Commerce Research and Applications, 16, 18-29, 2016. 
http://dx.doi.org/10.1016/j.elerap.2016.01.001

[73] C. Park and T. M. Lee, Information Direction, Website Reputation and eWOM Effect: A Moderating Role of Product Type. Journal of Business Research, 62(1), 61-67, 2009. http://dx.doi.org/10.1016/j.jbusres.2007.11.017

[74] H. D. Mcknight, C. J. Kacmar, and V. Choudhury, Shifting Factors and the Ineffectiveness of Third Party Assurance Seals: a Two-stage Model of Initial Trust in a Web Business. Electronic Markets, 14(3), 1-15, 2004. http://dx.doi.org/10.1080/1019678042000245263

[75] E. J. Lee and J. W. Overby, Creating Value for Online Shoppers: Implications for Satisfaction and Loyalty. Journal of Consumer Satisfaction, Dissatisfaction and Complaining Behavior, 17, 54-67, 2004.

[76] J. Wagner, Aesthetic Value: Beauty in Art and Fashion. In Consumer value: a framework for analysis and research, edited by M. Holbrook, 126-146. New York: Routledge Interpretive Marketing Research, 1991.

[77] W. B. Dodds, In Search of Value: How Price and Store Name Information Influence Buyers' Product Perceptions. Journal of Services Marketing, 5(3), 27-36, 1991. http://dx.doi.org/10.1108/07363769110034974

[78] A. E. Cretu and R. J. Brodie, The Influence of Brand Image and Company Reputation Where Manufacturers Market to Small Firms: A Customer Value Perspective. Industrial Marketing Management, 36(2), 230-240, 2007. http://dx.doi.org/10.1016/j.indmarman.2005.08.013

[79] G. Moss, R. Gunn, and J. Heller, Some Men Like It Black, Some Women Like It Pink: Consumer Implications of Differences in Male and Female Website Design. Journal of Consumer Behavior, 5(4), 328-341, 2006. http://dx.doi.org/10.1002/cb.184

[80] W. S. Kwon, and S. J. Lennon, What Induces Online Loyalty? Online Versus Offline Brand Images. Journal of Business Research, 62(5), 557-564, 2009. http://dx.doi.org/10.1016/j.jbusres.2008.06.015

[81] X. Zhao, A.S. Mattila, and L.-S. Eva Tao, The role of post-training self-efficacy in customers' use of self-service technologies. International Journal of Service Industry Management, 19(4), 492-505, 2008. http://dx.doi.org/10.1108/09564230810891923

[82] C.-M. Chiu, Sun, S.-Y., Sun, P.-C., \& Ju, T. L., An empirical analysis of the antecedents of web-based learning continuance. Computers \& Education, $\quad 49(4), \quad 1224-1245, \quad 2007$. http://dx.doi.org/10.1016/j.compedu.2006.01.010

[83] M.-H. Hsu, C.-M. Chang, K.-K. Chu, and Y.-J. Lee, Determinants of repurchase intention in online group-buying: The perspectives of DeLone \& McLean IS success model and trust. Computers in Human 
Behavior, 36 , 234-245,

2014. http://dx.doi.org/10.1016/j.chb.2014.03.065

[84] E.C. Ku, and C.-D. Chen, Fitting facilities to self-service technology usage: evidence from kiosks in Taiwan airport. Journal of Air Transport Management, 32, 87-94, 2013. http://dx.doi.org/10.1016/j.jairtraman.2013.07.001

[85] R. Batra, O. T. Ahtola, Measuring the hedonic and utilitarian sources of consumer attitude, Marketing Letters, Vol. 2 No. 2, pp. 159-170, 1991. http://dx.doi.org/10.1007/BF00436035

[86] C. Fornell and D. F. Larcker, Evaluating Structural Equation Models with Unobservable and Measurement Error. Journal of Marketing, 18(1), 39-50, 1981.

[87] R. Bagozzi and L. Phillips, Assessing Construct Validity in Organizational Research. Administrative Science Quarterly, 36(3) 421-458, 1991. http://dx.doi.org/10.2307/2393203

[88] H. Wold, Introduction to the second generation of multivariate analysis. In H. Wold, Editor, Theoretical Empiricism, NY: Paragon House, 1989.

[89] R. Tompson, D. W. Barclay \& C. A. Higgins, The partial least squares approach to causal modeling: Personal computer adoption and uses as an illustration. Technology Studies: Special Issue on Research Methodology, 2(2), 284-324, 1995.

[90] W. W. Chin, Issues and opinion on structural equation modeling, MIS Quarterly, 22(1), 7-16, 1998.

[91] E. M. Okada, Justification Effects on Consumer Choice of Hedonic and Utilitarian Goods. Journal of Marketing Research, 42(1), 43-53, 2005. http://dx.doi.org/10.1509/jmkr.42.1.43.56889

[92] L. Zhao, Y. Lu, L. Zhang, and P. Y. K. Chau, Assessing the Effects of Service Quality and Justice on Customer Satisfaction and the Continuance Intention of Mobile Value-added Services: An Empirical Test of a Multidimensional Model. Decision Support Systems, 52(3), 645-656, 2012. http://dx.doi.org/10.1016/j.dss.2011.10.022

[93] T. Zhou, Understanding Continuance Usage of Mobile Services. International Journal of Mobile Communications, 11(1), 56-70, 2013. http://dx.doi.org/10.1504/IJMC.2013.050995

[94] J. Coutaz, J. L. Cowley, S. Dobson, and D. Garlan, Context is Key. Communications of the ACM, 48(3), 49-53, 2005. http://dx.doi.org/10.1145/1047671.1047703

[95] Y. T. Chen and T. Y. Chou, Exploring the Continuance Intentions of Consumers for B2C Online Shopping: Perspectives of Fairness and Trust. Online Information Review, 36(1), 104-125. 2012. http://dx.doi.org/10.1108/14684521211209572 